\title{
Anthropometric and physical fitness parameters versus specific performance tests in Brazilian field hockey athletes: a pilot study
}

\author{
Raquel Silva Lemos ${ }^{1}$, Gabriel Andrade Paz ${ }^{1,2}$, Marianna de Freitas Maia ${ }^{1,2}$, Jurandir Baptista da \\ Silva ${ }^{2,3}$, Vicente Pinheiro Lima ${ }^{2,3}$, Juliana Brandão Pinto de Castro ${ }^{3}$, Humberto Miranda ${ }^{1}$
}

${ }^{1}$ School of Physical Education and Sports, Federal University of Rio de Janeiro, Rio de Janeiro, Brazil; ${ }^{2}$ Biodynamic Laboratory of Exercise, Health and Performance, Castelo Branco University, Rio de Janeiro, Brazil; ${ }^{3}$ Institute of Physical Education and Sports, Postgraduate Program in Exercise and Sport Sciences, State University of Rio de Janeiro, Rio de Janeiro, Brazil

\section{Summary}

Study aim: To investigate the correlation between anthropometric parameters, Sargent jump test, core muscles endurance and agility performance versus specific tests with and without a ball in female Brazilian field hockey athletes.

Material and methods: Nine professional female field hockey players (age: $27.4 \pm 2.5$ years) participated in this study. Body height, body weight, body fat percentage, Sargent jump test (SJT), shuttle run agility test (SR), core muscular endurance tests and sport-specific tests - repeated sprint ability test (RSA) and repeated sprint ability with the ball (RSAB) - were assessed in a randomized order.

Results: A moderate correlation was noted between SR and RSAB $(r=0.58, \mathrm{p}=0.09)$ and $\mathrm{RSA}(\mathrm{r}=0.60, \mathrm{p}=0.08)$. In addition, a moderate correlation was noted between percentage of body fat with $\operatorname{RSAB}(r=0.59, \mathrm{p}=0.09)$ and with $\operatorname{RSA}(\mathrm{r}=0.72$, $\mathrm{p}=0.08)$. The other variables showed slight agreement or no agreement.

Conclusions: These results indicated that the SR could be implemented in training and evaluation programs of hockey athletes due to the correlation with specific tests. Thus, the percentage of body fat was the only anthropometric parameter that showed a correlation with the specific tests, revealing the importance of maintaining a proper percentage of body fat for better performance in hockey.

Keywords: Hockey - Physical Fitness - Female - Athletes - Body Composition

\section{Introduction}

Field hockey is an Olympic sport often performed in European countries which been growing in Brazil. The rules of this sport contribute to a game with a lot of dynamism and high-intensity tasks. Field hockey is an intermittent endurance sport involving sprints and movements with and without a ball [19]. In addition, hockey is a game that demands great physiological capacity, because the hockey player needs to achieve high levels of muscle power for sprints, as well as a good capacity of the aerobic system [10].

Physical fitness for performance is a term with different definitions. However, physical fitness in sport has a more specific definition, and its correlation with performance has been investigated in previous studies $[2,9,13,23$,
24, 27]. In this sense, some components needed to practice field hockey at a high level of performance are: agility to perform quick changes of direction without loss of speed, efficiency to recover between sprints, endurance of the stabilizing muscles of the spine to maintain the adopted posture during practice, and technical skills [18].

In addition, body composition and anthropometric characteristics, such as body height, body weight, body mass index (BMI), hip circumference and abdominal fat percentage, are important components for sports performance. Correlations between these variables and sports performance are widely related in the scientific literature in several sports $[9,14,15,29,30,34]$.

Thus, specific evidence about these variables is important and may contribute to prescription, monitoring and improvement of athletic performance of hockey athletes [32]. Several studies have investigated the correlations 
between anthropometric variables and physical fitness and specific skill tests in various sports, such as handball [1], basketball [11], volleyball [6], and soccer [31]. Also in this context, Koley et al. [16], Singh et al. [32] and Keogh et al. [15], with the goal of quantifying the performance of hockey athletes, evaluated the anthropometric variables, such as body height, body weight, and body mass index (BMI), and their association with specific tests and physical fitness parameters. Positive associations were found between BMI and specific tests, and also between BMI, body height and muscle performance tests. However, there is still a lack of evidence associated with specific performance parameters of field hockey athletes using low-cost procedures.

Thus, there is a clear need to verify the physical fitness and body composition indices of field hockey athletes, as well as to understand the possible association of these factors with specific performance tasks. Therefore, the purpose of the present study was to investigate the correlation between anthropometric parameters (body height, body weight, BMI, and body fat percentage), the Sargent jump test, core muscles endurance, and uniplanar agility (shuttle run) versus specific tests (repeated agility tests) in professional Brazilian female field hockey athletes.

\section{Materials and methods}

\section{Subjects}

Nine female professional field hockey athletes of a Rio de Janeiro hockey club participated in this study. To be included in the study, a subject had to: a) practice hockey for at least three years; b) have previous experience in the tests applied in this study; c) participate in national competitions for at least three years. Individuals who attended less than two sessions per week and who used alimentary supplementation were excluded from the study. The characteristics of the sample are represented in Table I as mean and standard deviation.

This project was submitted and approved by the institution ethics committee. Therefore, this study met the standards for conducting research on human beings in accordance with the National Health Council of Brazil [7] and the Declaration of Helsinki [35]. All participants signed an informed consent form.

\section{Procedures}

The group was subjected to one day of assessments in randomized design. First, anthropometric measures were performed to characterize the sample. Measurements of body weight were assessed through a mechanical balance (Filizola, Brazil), and body height was assessed using a portable stadiometer (Seca, Baystate Scale \& Systems, USA). In addition, the BMI was computed. Anthropometric measurements were assessed following the rules of the International Society for the Advancement of Kinanthropometry (ISAK) [20]. The body fat percentage was calculated according to the protocol of seven skinfolds [12].

For the analysis of specific performance, the athletes were evaluated in the following tests adopting in a randomized design: a) Sargent jump test (SJT); b) shuttle run agility test (SR); c) repeated sprint ability (RSA); d) repeated sprint ability with the ball (RSAB); e) core muscular endurance tests. Ten minutes of passive recovery was adopted between each test. The general warm-up consisted of six full turns in the RSA circuit with submaximal speed.

\section{Sargent jump test}

Firstly, the subject took the standing position, keeping aside a graduated surface with the right shoulder flexion of $180^{\circ}$ and elbow in extension to the brand was registered for the initial test. Secondly, the distal phalanx of the middle finger of each subject was covered with chalk to represent the highest point reached on the wall surface. Then, during the downward phase of the vertical jump (VJ), the subjects performed and held the flexion of the hips and knees, with the pendulum motion of flexion, extension and hyperextension of the shoulders. In the ascending phase, extension of the ankle, knee and hip was carried out and, bending the shoulders in order to jump as high as possible, touching the middle finger in the graduated wall surface. Throughout the test, it was not allowed to move the feet before the VJ and the subjects were instructed to perform a full knee extension during the aerial part of the jump. Three attempts were allowed, with 2-min intervals between them. The greatest value in centimeters between the three attempts was recorded [33].

\section{Shuttle run}

The SR consists in running as fast as possible for a distance of 9.14 meters marked with two parallel

Table 1. Characteristics of the sample

\begin{tabular}{lccccc}
\hline & Age [years] & Weight $[\mathrm{kg}]$ & Height $[\mathrm{cm}]$ & BMI & $\%$ BF \\
\hline Mean \pm SD & $27.4 \pm 2.5$ & $62.1 \pm 2.6$ & $162.2 \pm 10.1$ & $22.9 \pm 1.3$ & $24.1 \pm 3.6$ \\
\hline
\end{tabular}

$\mathrm{SD}$ - standard deviation; BMI - body mass index; \%BF - percentage of body fat 
lines drawn on the floor and marked by an outside edge where there are two small cones, about $10 \mathrm{~cm}$ from the outside line, with a distance of $30 \mathrm{~cm}$ between the two cones [28]. The subjects should be on the opposite side of the line where the cones are positioned. At their top speed, the athletes should get one of the cones, return to the starting point, leave to catch the other cone and return. Running as fast as possible, they should take one of the cones and return to the starting point. The test ends when the individual puts the second cone on the floor and crosses the end line with one foot. Time is marked with a chronometer [28].

\section{Repeated sprint ability}

The RSA [4] consists of a circuit which simulates the variables of a hockey game (Fig. 1). The circuit includes three maximal sprints, one part of agility, three periods of walk and two trotting routes. A deceleration is made at the end of the circuit before the total stop. The circuit begins with a sprint of 20 meters. Then, 6 meters of agility are made in a zigzag ( 2 meters). A walk of 10 meters and a trot of 10 meters are made and then another sprint of 10 meters. After a pause of 2 seconds, the subject should restart with a walk of 10 meters and an accelerating walk of 30 meters, one sprint of 10 meters and, to finish, 5 meters of trot and 5 meters of walk (deceleration). The test was performed with the specific ball and stick of field hockey (RSAB) and without a ball (RSA).

\section{Core muscular endurance tests}

These tests consist of measuring the maximum time the subject can remain in a certain isometric position. Each individual has three attempts and a one-minute interval between attempts. The individual should be in four different positions: a) prone bridge test; b) side bridge tests; c) flexor endurance test; d) extensor endurance test [21].

In the prone bridge test (PB) and in the side bridge tests the subject assumes a prone position on the floor. After the signal of the instructor, a prone bridge position with elbows placed beneath the shoulders and arms perpendicular to the floor is assumed. In this position, only the feet and the forearms touch the floor.

The side bridge tests involved the right side bridge (RSB) and the left side bridge (LSB). These tests consisted of subjects lying on an exercise mat (thickness of $2.5 \mathrm{~cm}$ ) on their sides with legs extended. The top foot was placed in front of the lower foot on the mat for support. Subjects were instructed to support themselves lifting their hips off the mat to maintain a straight line over their full body length, and support themselves on one elbow and their feet. The uninvolved arm was held across the chest with the hand placed on the opposite shoulder. The test ended when the hips returned to the exercise mat.

In the flexor endurance test (FE), the subjects had to sit on the test bench and place the upper body against a support with an angle of $60^{\circ}$ from the test bed. Both knees and hips were flexed to $90^{\circ}$. The arms were folded across the chest with the hands placed on the opposite shoulder and the toes were placed under toe straps. Subjects were instructed to maintain the body position while the supporting wedge was pulled back $10 \mathrm{~cm}$ to begin the test. The test ended when the upper body fell below the $60^{\circ}$ angle.

In the extensor endurance test (EE), the subjects lay in a prone position with the lower body fixed to the test bed at the ankles, knees, and hips and the upper body extended in a cantilevered fashion over the edge of the test bench. Subjects rested their upper bodies on the floor before the exertion. At the beginning of the exertion, the upper limbs

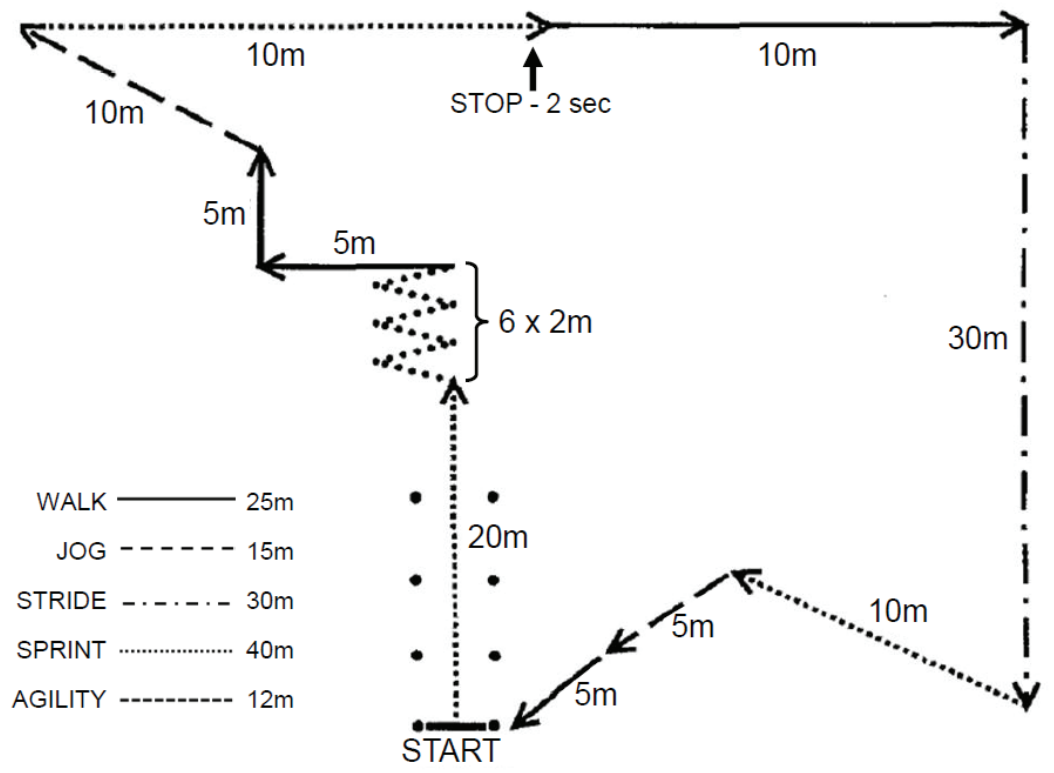

Fig. 1. Schematic drawing of the repeated spring ability test 
were held across the chest with the hands resting on the opposite shoulders, and the upper body was lifted off the floor until the upper torso was horizontal to the floor. Subjects were instructed to maintain the horizontal position as long as possible. The endurance time was manually recorded in seconds with a chronometer from the point at which the subject assumed the horizontal position until the upper body came into contact with the floor.

\section{Statistical analyses}

In the descriptive statistics, the dependent variables were calculated and described as the mean and standard deviation. In inferential statistics, the intraclass correlation coefficient (ICC) was applied to test the reproducibility of attempts in each performance test. As validation, coefficients between 0.90 and 0.98 were adopted. To test the rejection or no rejection of the normal distribution of sample data we applied the Shapiro-Wilk test. The Pearson correlation was adopted to analyze the dependent variables. The agreement level was classified as proposed by Landis and Koch [17] and determined as follows: trivial, $<0.10$; small, $\leq 0.10-0.29$; moderate, 0.30-0.49; large, 0.50-0.69; very large, $0.70-0.89$; and nearly perfect, $0.90-0.99$. The paired t test was adopted to compare the muscle endurance between RSB and LSB. The level of $\alpha=0.05$ was adopted for statistical significance. All statistical analysis was performed using IBM SPSS Statistics 20 for Windows.

\section{Results}

The intraclass correlation coefficient, the confidence interval and the method error for all tests were inserted in Table 2. The results of SR, RSA, RSAB, SJT, PB, RSB, LSB, EE and FE are presented in Table 3 as mean and standard deviation. No difference was noted in muscle endurance performance between RSB and LSB tests.

According to the analysis of results (Table 4), a correlation was found between SR and RSAB (moderate agreement; $r=0.58$ ) and RSA (substantial agreement; $r=0.60$ ). We also found a correlation between percentage of body fat and RSAB (moderate agreement; $r=0.59$ ) and with RSA (substantial agreement; $r=0.72$ ). The other variables showed slight agreement or no agreement.

Table 2. Intraclass correlation coefficient (ICC), confidence interval (CI), and method error (ME) of physical performance tests measurement for intrasubject reliability $(\mathrm{N}=9)$

\begin{tabular}{lccccccccc}
\hline & SR & VJ & RSA & RSAB & PB & RSB & LSB & EE & FE \\
\hline ICC & 0.93 & 0.90 & 0.92 & 0.91 & 0.93 & 0.88 & 0.89 & 0.88 & 0.91 \\
$95 \%$ CI & $(0.64,0.94)$ & $(0.66,0.93)$ & $(0.66,0.94)$ & $(0.72,0.96)$ & $(0.73,0.93)$ & $(0.63,0.94)$ & $(0.64,0.96)$ & $(0.64,0.97)$ & $(0.63,0.98)$ \\
ME(CVME) & $2.0(2.6)$ & $2.4(2.5)$ & $2.9(3.2)$ & $2.0(2.9)$ & $2.0(2.9)$ & $2.0(2.9)$ & $2.5(2.9)$ & $2.5(2.6)$ & $2.5(2.6)$ \\
\hline
\end{tabular}

CVME - coefficient of variation of method error (percent variation in measurement between trials; SR: shuttle run; VJ - vertical jump; RSA - repeated spring ability test; RSAB - repeated spring ability test with ball; PB - prone bridge; RSB - right side bridge; LSB - left side bridge; EE - extensor endurance test; FE - flexor endurance test.

Table 3. Mean and standard deviation of performance tests applied in field hockey athletes

\begin{tabular}{lccccccccc}
\hline & SR [sec] & RSAB [sec] & RSA [sec] & SJT [cm] & PB [sec] & RSB [sec] & LSB [sec] & FE [sec] & EE [sec] \\
\hline Mean & 10.7 & 36.9 & 32.6 & 40 & 89.6 & 47.4 & 45.4 & 38.9 & 72.7 \\
$(\mathrm{SD})$ & $(0.6)$ & $(3.3)$ & $(3.0)$ & $(10.2)$ & $(17.6)$ & $(11)$ & $(13.1)$ & $(21.2)$ & $(16.7)$ \\
\hline
\end{tabular}

SD - standard deviation; SR - shuttle run; RSAB - repeated sprint ability test with ball; RSA - repeated sprint ability test; SJT - sargent jump test; PB - prone bridge; RSB - right side bridge; LSB - left side bridge; FE - flexor endurance test; EE - extensor endurance test.

Table 4. Correlation (r value) between the core endurance test and vertical jump in relation to RSAB and RSA

\begin{tabular}{|c|c|c|c|c|c|c|c|c|c|c|c|}
\hline & SR & SJT & PB & RSD & LSE & $\mathrm{FE}$ & $\mathrm{EE}$ & Weight & Height & BMI & $\% \mathrm{BF}$ \\
\hline RSAB & 0.58 & -0.11 & -0.77 & -0.37 & 0.01 & -0.04 & 0.05 & -0.06 & 0.17 & -0.23 & 0.59 \\
\hline RSA & 0.60 & -0.37 & -0.69 & -0.45 & -0.15 & -0.02 & 0.20 & -0.08 & 0.07 & -0.03 & 0.72 \\
\hline
\end{tabular}

SR - shuttle run; SJT - sargent jump test; PB - prone bridge; RSB - right side bridge; LSB - left side bridge; FE - flexor endurance test; EE extensor endurance test; $\mathrm{BMI}$ - body mass index; \%BF - percentage of body fat. 


\section{Discussion}

The purpose of the present study was to investigate the correlation between anthropometric parameters (body height, body weight, body mass index, and body fat percentage), Sargent jump test, core muscles endurance, and uniplanar agility (shuttle run) versus specific tests (repeated agility tests) in professional Brazilian female field hockey athletes. The main finding of the study was the moderate correlation of the SR test with RSAB and RSA. Thus, the body fat percentage was the only anthropometric parameter which presented a correlation with RSA and RSAB tests.

The present study revealed a moderate correlation between body fat percentage and the specific hockey tests (RSA and RSAB). In this context, body fat percentage measurement is an important anthropometric marker often assessed in sport conditioning programs. Keogh et al. [15] evaluated the association between anthropometric variables and performance in physical fitness tests comparing recreational athletes to elite athletes. Greater values in the vertical jump test, multistage fitness test, and $10 \mathrm{~m}$ and $40 \mathrm{~m}$ speed tests were observed in subjects with the lowest percentage of fat (elite group). This corroborates the results found in the present study, confirming the evidence reported by Bale and McNaught-Davis [3], which characterized the elite field hockey athletes as mesomorphs. Despite the association between body composition and sport performance, this result should be interpreted with caution, especially in relation to specific motor tasks such as multiplanar agility.

The athletes of the present study performed the SR test, which is similar to the multiple shuttle test (uniplanar agility). This test was used by Boddington et al. [5], who also applied physical fitness tests to assess the specific performance of 14 female field hockey athletes. The multiple shuttle test consists of a circuit totaling five meters and analyzes the agility and speed of the athletes. However, besides the speed and agility tests, the specific tests for each sport such as RSA provide broad practical application to coaches and sport conditioning professionals during the assessment or workout sessions. Nevertheless, the results obtained in the present study showed a moderate association between the values obtained in SR and RSA. Thus, the data suggest that, in this particular case, both tests can be included in separate moments of the preparation in order to evaluate and train the agility skill.

Although field hockey is a game that requires the performance of several sprints and, consequently, lower body muscle power, there was no correlation between the SJT and specific field hockey tests (RSA and RSAB) in the present study. According to Nikolaidis et al. [25], sprint ability is a major component of performance and can be used in talent identification and in the selection of players. However, the results of the present study differ from the findings of Dal Pupo et al. [8], who found a correlation between the vertical jump test, sprint test, and agility test in young soccer players. The agility skill is influenced and affected by several mechanisms including neural processing, muscle coordination, power, and anaerobic performance. However, due to the flexed trunk position adopted in field hockey, the horizontal force vector is higher than vertical. This is one aspect which may explain the lack of association between vertical power and the specific tests applied in the present study. On the other hand, field hockey implies a body position (i.e. trunk flexed) which overloads the low back. This condition requires a high level of endurance of core muscles to improve spine stabilization, minimize compression overload and prevent injuries [22]. However, in the present study, the hockey athletes showed endurance levels below the average proposed by McGill [21] for all tests measured (prone bridge, lateral bridges, flexor endurance, and extensor endurance). The athletes presented the ratio of flexion/extension endurance (0.72) and right/ left bridge (0.98) near the values described as normal, 0.72 and 0.96 respectively. However, the extension/right side bridge ratio (0.59) and the extension/left side bridge ratio $(0.62)$ had scores above the values proposed by McGill [21] (0.40 and 0.42). These results indicate instability of these muscles in the spine region. Ogurkowska et al. [26] evaluated the condition of the lumbar spine among 20 male field hockey players of the Polish national team, aged between 24 and 35 years. These athletes trained field hockey between 14 and 26 years. They used CT scans to determine the height of vertebrae and intervertebral discs and found degeneration in the vertebral discs in these field hockey athletes. Additionally, the results of the current study showed that even in elite athletes of field hockey, poor levels of core muscle endurance can occur. In this sense, the implementation of base and integrated core exercises is essential during the prescription of training programs for field hockey athletes with the goal of preventing spine injuries.

This study had some limitations. The sample size $(n=9)$ was small, which may limit the external validation of our findings. However, field hockey is a team sport emerging in Brazil, and the female athletes evaluated in the present study had often participated in national and international high level competitions for at least six years. In addition, the tests and procedures adopted in the current study can be easily applied in gyms and training centers at low cost. These conditions are essential to improve the performance and development of field hockey athletes, especially in countries which experience a low level of financial investments. 


\section{Conclusions}

In conclusion, the results of this study showed a correlation between SR and hockey-specific tests (RSA and RSAB). Thus, the body fat percentage was the only anthropometric parameter that showed a correlation with a specific test, indicating percentage interesting body composition variable to be monitored with the goal of improving agility performance in field hockey athletes. On the other hand, the athletes showed a lower level of core muscle endurance, considering the normative values for recreational subjects. Therefore, uniplanar agility (i.e., shuttle run test) and body fat percentage may be key variables to be monitored during the screening and training prescription of female hockey athletes.

\section{Conflict of interest: Authors state no conflict of interest.}

\section{References}

1. Alvares P.D., A.D. Reis, R.R. Diniz, F.A. Lima, M.C.R. Soares, G.B. Pereira (2014) Relação do perfil antropométrico com a força e agilidade de jogadores de handebol. Rev. Bras. Presc. Fisiol. Exercício, 8: 354.

2. American College of Sports Medicine (2014) ACSM's resource manual for guidelines for exercise testing and prescription. 7th ed. USA: Lippincott Williams \& Wilkins. p. 39.

3. Bale P., P. McNaught-Davis (1983) The physiques, fitness and strength of top class women hockey players. J. Sports Med. Phys. Fitness, 23: 80-86.

4. Bishop D., S. Lawrence, M. Spencer (2003) Predictors of repeated-sprint ability in elite female hockey players. J. Sci. Med. Sport, 6: 199-209. DOI: 10.1016/S14402440(03)80255-4.

5. Boddington M.K., M.I. Lambert, M.R. Waldeck (2004) Validity of a 5-meter multiple shuttle run test for assessing fitness of women field hockey players. J. Strength Cond. Res., 18: 97-100.

6. Cabral S.A.T., B.G.A.T. Cabral, V.C.M. Pinto, R.D. Andrade, M.V.O. Borges, P.M.S. Dantas (2016) Relação da idade óssea com antropometria e aptidão física em jovens praticantes de voleibol. Rev. Bras. Ciênc. Esporte, 38: 69-75. DOI: 10.1016/j.rbce.2015.12.003.

7. Conselho Nacional de Saúde (Brasil). Resolução no 466, de 12 de dezembro de 2012. Diário Oficial da União, Brasília, DF, n. 12, p. 59, jun. 2013.

8. Dal Pupo J., D. Detanico, F.B. Arins, P.C.N. Salvador, L.G.A. Guglielmo, S.G. Santos (2016) Repeated sprint ability and muscle power levels of the futsal players of U15 and U17 categories. Rev. Bras. Ciênc. Esporte, 1-6. DOI: 10.1016/j.rbce.2016.01.010.
9. Deprez D., J. Fransen, M. Lenoir, R.M. Philippaerts, R. Vaeyens (2015) A retrospective study on anthropometrical, physical fitness and motor coordination characteristics that influence drop out, contract status and first-team playing time in high-level soccer players, aged 8 to 18 years. J. Strength Cond. Res., 29: 1692-704. DOI: 10.1519/JSC.0000000000000806.

10. Elferink-Gemser M.T., C. Visscher, M.A.J. Van Duijn, K.A.P.M. Lemmink (2006) Development of the interval endurance capacity in elite and sub-elite youth field hockey players. Br. J. Sports Med., 40: 340-345. DOI: 10.1136/bjsm.2005.023044.

11. Gomes J.H., R.G. Chaves, A. Evangelista, M.A. Charro, D.S. Bocalini, A.J. Figueira Junior (2015) Relationship between anthropometrics, physical performance and game statistics in young elite basketball players. Rev. Bras. Ciênc. Mov., 23: 66-73. DOI: 10.18511/0103-1716/ rbcm.v23n2p66-73.

12. Jackson A.S., M.L. Pollock (1978) Generalized equations for predicting body density of men. Br. J. Nutr., 40: 497-504.

13. Johnston R.D., T.J. Gabbett, D.G. Jenkins (2015) The influence of physical fitness and playing standard on pacing strategies during a team-sport tournament. Int. J. Sports Physiol. Perform., 10: 1001-1008. DOI: 10.1123/ ijspp.2015-0005.

14. Karkare A. (2011) Anthropometric measurements and body composition of hockey players with respect to their playing positions. Ind. Str. Res. J., 1: 5-8.

15. Keogh J.W.L., C.L. Weber, C.T. Dalton (2003) Evaluation of anthropometric, physiological, and skill-related tests for talent identification in female field hockey. Can. J. Appl. Physiol., 28: 397-409. DOI: 10.1139/h03029.

16. Koley S., J.H.A. Santosh, J.S. Sandhu (2012) Study of back strength and its association with selected anthropometric and physical fitness variables in inter-university hockey players. Anthropologist, 14: 359-363.

17. Landis J.R., G.G. Koch (1977) The measurement of observer agreement for categorical data. Biometrics, 33: 159-174.

18. Lemmink K.A.P.M., M.T. Elferink-Gemser, C. Visscher (2004) Evaluation of the reliability of two field hockey specific sprint and dribble tests in young field hockey players. Br. J. Sports Med., 38: 138-142. DOI: 10.1136/ bjsm.2002.001446.

19. Manna I., G.L. Khanna, P.C. Dhara (2009) Training induced changes on physiological and biochemical variables of young Indian field hockey players. Biol. Sport, 26: 33-43. DOI: 10.5604/20831862.890173.

20. Marfell-Jones M., T. Olds, A. Stewart, L. Carter (2006) International standards for anthropometric assessment. Potchefstroom, South Africa: ISAK. p. 51. 
21. McGill S. (2015) Low back disorders: evidence-based prevention and rehabilitation. 3rd ed. Champaign, IL: Human Kinetics. pp. 286-289.

22. Nikolaidis P. (2010) Core stability of male and female football players. Biomed. Hum. Kinet., 2: 30-33. DOI: 10.2478/v10101-010-0007-9.

23. Nikolaidis, P.T. (2011) Association between submaximal and maximal measures of aerobic power in female adolescents. Biomed. Hum. Kinet., 3: 106-110. DOI: 10.2478/ v10101-011-0023-4.

24. Nikolaidis P.T. (2014) Evaluation of fatigue in semiprofessional football players: association between overtraining and physical fitness. Biomed. Hum. Kinet., 6(1): 51-55. DOI: 10.2478/bhk-2014-0009.

25. Nikolaidis P.T., B. Knechtle, F. Clemente, G. TorresLuque (2016) Reference values for the sprint performance in male football players aged from 9-35 years. Biomed. Hum. Kinet., 8(1): 103-112. DOI: 10.1515/bhk2016-0015.

26. Ogurkowska M., K. Kawałek (2016) Pathological changes in the lumbar intervertebral discs among professional field hockey players. J. Sports Med. Phys. Fitness, 56: 85-91.

27. Opstoel K., J. Pion, M. Elferink-Gemser, E. Hartman, B. Willemse, R. Philippaerts, C. Visscher, M. Lenoir (2015) Anthropometric characteristics, physical fitness and motor coordination of 9 to 11 year old children participating in a wide range of sports. PLoS One, 10(5): e0126282. DOI: 10.1371/journal.pone.0126282.

28. Paz G.A., T.J. Gabbett, M.F. Maia, H. Santana, H. Miranda, V. Lima (2016) Physical performance and positional differences among young female volleyball players. J. Sports Med. Phys. Fitness.
29. Pion J., M. Lenoir, B. Vandorpe, V. Segers (2015) Talent in female gymnastics: a survival analysis based upon performance characteristics. Int. J. Sports Med., 36: 935-940. DOI: 10.1055/s-0035-1548887.

30. Scott PA. (1991) Morphological characteristics of elite male field hockey players. J. Sports Med. Phys. Fitness, 31: 57-61.

31. Silva J.E., J.C. Voltolini, R.S. Brito (2015) Relation between body mass, stature and $\mathrm{VO}_{2}$ max with measures of physical performance in football athletes. Rev. Bras. Futsal Futebol, 7: 59-66.

32. Singh M., K.M. Singh, K. Singh (2010) Anthropometric measurements, body composition and physical parameters of Indian, Pakistani and Sri Lankan field hockey players. Serb. J. Sports Sci., 4: 47-52.

33. Sisic N., M. Jelicic, M. Pehar, M. Spasic, D. Sekulic (2016) Agility performance in high-level junior basketball players: the predictive value of anthropometrics and power qualities. J. Sports Med. Phys. Fitness, 56: 884-893.

34. Stöggl R., E. Müller, T. Stöggl (2015) Motor abilities and anthropometrics in youth cross-country skiing. Scand. J. Med. Sci. Sports, 25: e70-81. DOI: 10.1111/sms.12254.

35. World Medical Association (1997) Declaration of Helsinki. Recommendation guiding physicians in biomedical research involving human subjects. JAMA, 277: 925-926.

\section{Received 11.01.2017 \\ Accepted 10.04.2017}

(C) University of Physical Education, Warsaw, Poland 